\title{
Informes a la Sociedad Colombiana de Obstetricia y Ginecología
}

INFORME DEL PRESIDENTE SALIENTE DE LA SOCIEDAD COLOMBIANA DE OBSTETRICIA Y GINECOLOGIA, DOCTOR GONZALO ECHEVERRY, EN LA SESION DEL DIA 11 DE FEBRERO DE 1959

Señores miembros de la Sociedad Colombiana de Obstetricia y Ginecología:

Como Presidente saliente, me cabe hoy el honor de rendiros el acostumbrado informe sobre la marcha de la institución durante el periodo reglamentario en que tuvísteis a bien confiar las actividades de la Sociedad a la Junta Directiva que hoy termina sus funciones.

En el año que acaba de pasar, nuestra Sociedad ha tenido una trayectoria que pudiéramos considerar normal, sin que se hayan presentado circunstancias especiales de ningún orden que alteraran el desarrollo ordinario de las finalidades que estatutariamente deben ser llenadas.

Hemos interpretado como contingencia especialmente aforiunada para esta Directiva saliente, el hecho de que durante nuestro mandato no hubieran ocurrido en la Sociedad problemas gremiales de importancia, lo cual nos permitió desenvolver todas las gestiones de directiva dentro de la tranquilidad y cordialicad inherentes a las sesiones científicas. Es claro que la Socieclad no olvidó sus funciones de entidad gremial, y en el curso de las emergencias, ocurridas a otra sociedad amiga en sus divergencias con el Instituto Colombiano de Seguros Sociales, la Directiva nuestra estuvo siempre presente en todas las reuniones y brindó su apoyo y colaboración a los otros colegas en la búsqueda de una solución a sus divergencias. Es lástima que después de tántos debates y esfuerzos de parte de todas las sociedades 
científicas de Bogotá, se hubiera llegado al fin a una solución tan incompleta y pobre.

Dentro del terreno de la función gremial de la Sociedad propiamente dicha, solo tenemos que deciros que el contrato que se mantiene con el Instituto Colombiano de Seguros Sociales para la prestación de los servicios obstétricos, continúa vigente de acuerdo con los términos estipulados en la reforma que se llevó a cabo en el año de 1957, y que en vista de las circunstancias reinantes en 1958, la Directiva no consideró en ningún momento oportuno tratar de buscar modificaciones a dicho contrato.

En cuanto se refiere a los servicios ginecológicos de los Seguros Sociales, tuvimos siempre el empeño en que éstos fueran contratados directamente por el Instituto con la Sociedad, en forma similar a como están contratados los servicios obstétricos, y al respecto se han realizado entrevistas y se ha mantenido correspondencia con las directivas de los Seguros Sociales. Desafortunadamente no hemos encontrado en los Seguros acogida suficiente para esta idea, por el hecho de que los servicios de cirugía ginecológica están involucrados por el Instituto dentro de los servicios de cirugía general y se ciñen a las reglamentaciones de éstos, y además porque los Seguros Sociales parten de la base de que para contratar tales servicios quirúrgicos sería indispensable que la sociedad asumiera todos los riesgos de responsabilidad civil eventualmente inherentes, cosa que la Sociedad no estaría en condiciones de aceptar. Por otra parte, el Instituto alega que el Seguro Social no puede en ningún momento desligarse del contrato individual de prestación que mantiene con cada uno de sus afiliados y que lo obliga a responder por posibles indemnizaciones, y siendo así que el Seguro es responsable civilmente, en la misma forma, dicen ellos, tiene que tener bajo su directo comando la prestación de los servicios de cirugía ginecológica y no puede delegarla en la Sociedad. Es claro que esto no está de acuerdo con el hecho de que los servicios obstétricos sí pueden serlo y estén contratados sin apelar a tales argumentaciones, pero el caso concreto es que todas las diligencias realizadas al respecto, pueden considerarse fracasadas. Sea éste el momento de poner en conocimiento de la Sociedad, el vigilante interés que nuestro Vicepresidente, doctor Héctor Henrique Bernal, ha tenido en todo instante por la mejor solución del problema en referencia, y sus afortunadas gestiones en favor de los ginecólogos que prestan sus servicios como cirujanos en el Instituto Colombiano de Seguros Sociales. 
También dentro del terreno gremial debemos hacer mención en este informe de la solución que la Sociedad dio por fin al antiguo diferendo con los obstetras que prestan o prestaron sus servicios en la Clínica de Maternidad "David Restrepo". Es de lamentar que estos especialistas, reintegrados a su condición de miembros de número de la Sociedad, no se hayan hecho presentes en las sesiones.

Las actividades científicas se desarrollaron normalmente. Se verificaron en el año, diez sesiones científicas ordinarias y una extraordinaria, en tal forma que solo hubo dos meses en los cuales no hubo sesión: el mes de abril, por una lamentable falta absoluta de quórum; y el mes de enero del presente año, porque deliberadamente no se hizo citación para tal mes. En todas las sesiones se dio lectura a algún trabajo científico sobre temas de la especialidad y afines, pero llama especialmente la atención el que tales trabajos fueran en su mayoría presentados y leídos por elementos médicos no pertenecientes a la Sociedad. Este hecho, y el ausentismo crónico y recidivante de la mayoría de los socios en las sesiones, son muestra palpable del escaso interés con que muchos de nuestros miembros ven la marcha de la institución. Tenemos fe en que la nueva Directiva contará con un mejor apoyo de parte de los socios.

En el terreno de las relaciones con las sociedades obstétricas y ginecológicas nacionales, se hizo todo lo que fue posible por lograr la aceptación de las sociedades de provincia para los estatutos de una gran Sociedad Colombiana de Obstetricia y Ginecología que englobara en su seno a todas las demás, estatutos que fueron aprobados en dos debates por nosotros, en sesión de hace precisamente un año. No estuvieron de acuerdo las presuntas sociedades seccionales en muchos puntos, y entonces se pensó en crear más bien una Federación Colombiana de Sociedades de la especialidad. Naturalmente, para lograr este fin seria necesario rehacer una vez más los estatutos en lo que se refiere a las seccionales, y proponerlos nuevamente a la aprobación de ellas. Esta modificación estatutaria fue propuesta por la Directiva, pero fue negada. Por estas razones seguimos funcionando en una forma que pudiéramos llamar totalmente independiente de las demás sociedades obstétricas y ginecológicas del país, y ellas siguen también independientes de nosotros.

En el terreno internacional, se pusieron al día las cuentas con FLASOG, cancelando saldos pendientes desde hacía cinco años, por concepto de derechos de afiliación. 
Se consiguió también el ingreso de nuestra Sociedad a la Federación Internacional de Sociedades de Obstetricia y Ginecología, mediante la aprobación que la asamblea general de dicha Federación, reunida en Montreal en junio de 1958, dio a nuestra solicitud de afiliación. La cuota correspondiente al primer año está debidamente cancelada. Consideramos éste un paso de gran trascendencia, por los benéficos resultados que seguramente tendrá para nosotros tan importante conexión internacional.

Durante el año, tuvimos el honor de tener como conferenciante al doctor Howard J. Tatun, a quien se concedió diploma de miembro correspondiente extranjero. Para este año está ya confirmada la aceptación de una conferencia del doctor Pierre Velay, de París, sobre un tema de métodos sicofísicos para el parto indoloro. Esta conferencia tendrá lugar el próximo mes de marzo, y creemos que para ella debe hacerse también una sesión extraordinaria.

Solo tuvimos en el año pasado dos solicitudes para ingreso de miembros de número. Una de ellas fue debidamente tramitada, y acaba de dársele el curso final con la aceptación del candidato. La otra no se pudo diligenciar debidamente porque los estatutos vigentes oponen obstáculos y la Directiva de una Sociedad no puede, en ningún caso, ir contra las determinaciones estatutarias. Ya, en esta sesión, acabáis de ser ampliamente informados del problema, y sería de desear que esta legislación quedara debidamente clara para que en posteriores ocasiones pueda darse fácil trámite al ingreso de nuevos socios.

Se recibió también en el año pasado a un socio afiliado. A este respecto, consideramos también importante que en los estatutos se expresen claramente las funciones, deberes y derechos de dichos socios, pues en realidad no está esto claramente determinado.

La Sociedad Colombiana de Obstetricia y Ginecología fue distinguida el año pasado con la designación hecha por la FLASOG como entidad organizadora y sede para el IV Congreso Latinoamericano de Obstetricia y Ginecologia, y para la correspondiente Asamblea General de la Federación. Ya se han dado los primeros pasos conducentes a esta grave responsabilidad que afronta nuestra institución, y se encuentra debidamente constituído y operando el Comité Central Directivo del IV Congreso. Se autorizó, igualmente, a dicho Comité para recabar de los socios un préstamo en dinero, con el objeto de atender a los primeros gastos de la organización. Este préstamo fue debidamente 
atendido por los socios que actúan como obstetras en el Instituto Colombiano de Seguros Sociales, y esperamos que también 'os haya sido o vaya a serlo muy pronto por los demás socios.

En relación con el IV Congreso Nacional de la especialidad ya sabéis vosotros cómo la sede designada, que era la ciudad de Santa Marta, no pudo o no quiso afrontar la organización del certamen. Se consiguió que la Sociedad de Obstetricia y Ginecología del Atlántico aceptara la sede para Barranquilla, y se han Enviado, a la mencionada Sociedad, todas las informaciones $y$ ciatos que se nos han solicitado. Queda al buen cuidado de la Directiva entrante el trabajar y velar porque estos dos Congresos futuros lleguen a feliz culminación.

Hasta aquí, señores socios, el resumen de las actividades desarrolladas por nuestra Sociedad en el período que actualmente termina. La Directiva saliente tiene la satisfacción de entregar a. los distinguidos colegas que de hoy en adelante regirán la Sociedad un balance que, si en realidad no arroja resultados especialmente positivos en relación con notorios progresos científicos, por lo menos nos deja un pequeño saldo favorable en el sentido de que se trató de mantener la finalidad científica de la institución, en abierta y desigual lucha contra la indiferencia glacial de muchos de sus miembros. Todas las cuestiones mayoresc menores dependientes de la Junta Directiva quedan debidamente diligenciadas y resueltas, y solo entregamos pendientes. aquellos asuntos que por su misma naturaleza son de posterior culminación.

Como Presidente saliente, no quiero pecar de ingrato al dejar de reconocer y elogiar ante la sociedad la labor altamente encomiable de mis compañeros de Directiva, quienes con la más excelente buena voluntad y con un interés y cariño especiales para la institución, le prestaron en todos los momentos, lo mejor ce sus grandes capacidades para su buena y armoniosa marcha. Graciás a la buena colaboración de estos excelentes compañeros han sido posibles los modestos logros que en el curso del año hayamos podido obtener.

La Directiva saliente se despide de la Sociedad, agradeciendo muy especialmente a todos y a cada uno de los socios la distinción y el honor que le hicieran al encomendarle para este período la dirección de los destinos de la institución. Presenta sus excusas por las deficiencias que involuntariamente hayan ocurrido, y sus mejores votos porque, bajo el inteligente y acertado 
comando de la nueva Junta Directiva, la Sociedad continúe avanzando firmemente por el derrotero de triunfos y de éxitos científicos a que la creemos acreedora.

Doctor Gonzalo Echeverry

\section{INFORME DE LA DIRECTIVA DE LA REVISTA}

(Presentado en la Asamblea General de la Sociedad Colombiana de Obstetricia y Ginecología, el 11 de febrero de 1959).

Tenemos el orgullo de presentar a la Sociedad Colombiana de Obstetricia y Ginecología el presente informe de las labores que como directores de la Revista Colombiana de Obstetricia $y$ Ginecología llevamos a cabo de febrero del 58 a febrero del 59.

Continuando el derrotero seguido durante el año 57-58, y gracias al voto de confianza dado por las directivas de la Sociedad, al insistir sobre nuestra reelección para el período 58-59 y que en este momento toca a su fin. Debemos declarar que no hicimos otra cosa por todos los medios y con todo nuestro interés, que levantar el nivel científico de su importante publicación.

De tal manera estimulados, y a pesar de las limitaciones impuestas en más de una ocasión por el excesivo y creciente aumento del costo de impresión, podemos claramente analizar uno a. uno todos los puntos que juzgamos oportuno anotar.

\section{COLABORACIONES}

El material científico publicado, que alcanzó al número de treinta y tres artículos originales, fue en su mayor parte constituído por ponencias y trabaajos presentados al III Congreso de la especialidad, reunido en Ibagué en diciembre del 57.

El número de autores que colaboraron fue de 51, de los cuales 4 fueron extranjeros. Los puntos tratados en los artículos. versaron en su gran mayoría sobre temas motivo de las ponencias presentadas al III Congreso; considerando como números especiales el número 2, sobre toxemia gravídica; el número 4 . sobre carcinoma intra-epitelial, y el número 5, sobre mastopatías; números que constituyen por si solos verdaderos textos de consulta de los avances sobre tales temas.

DIFUSION DE LA REVISTA

De acuerdo con documentos que reposan en nuestro archivo, podemos asegurar que la Revista Colombiana de Obstetricia y Gi- 
necología tiene en el momento actual, un grado de difusión mundial digna de tenerse en cuenta. En efecto, de cada número publicado, se están enviando cerca de 200 ejemplares a los principales centros especializados, universitarios o a publicaciones afines de Europa y América. De la misma manera el canje que con revistas nacionales y extranjeras existe, ha llegado al número nada despreciable de 67, las cuales reposan en nuestra biblioteca, debidamente clasificadas y que solamente esperan ser consultadas por aquellos de los socios que se interesen por los artículos publicados en ellas.

Como donaciones especiales efectuadas a la biblioteca de la Revista, figuran: una colección de trabajos publicados por el Instituto Uruguayo de Fisiología Obstétrica "Bernardo Houssay", enviada amablemente por los doctores Hermógenes Alvarez y Juan Poseiro, y dos ejemplares publicados por el editorial Facta de Valencia, España, sobre pediatría y urología; los cuales fueron comentados en sección especial de nuestra Revista, dedicada a tales comentarios y creada con el único objeto de por éste medio acrecentar el número de volúmenes que en un futuro sea la iniciación de una biblioteca bien equipada.

CARACTERISTTCAS DEL VOLUMEN IX

Bajo este título queremos hacer resaltar una serie de hechos que demuestran el progreso logrado durante el período 58-59 en nuestra publicación.

El número de páginas (588) que corresponde al volumen IX, del cual nos ocupamos en este momento, alcanzó al del volumen $\mathrm{V}$, el cual fue numerado incluyendo en él al libro de las Memorias del I Congreso, celebrado en Bogotá en 1953 y que constaba él solo de 318 páginas.

El número de grabados que, como se sabe, aumenta el costo de publicación, fue de 99, entre microfotografías, fotografías de casos, diagramas, etc. Sin dejar de señalar la clase de papel sobre el cual fueron presentados, que durante todo el volumen se tendió a mejorar.

\section{COSTOS DE PUBLICACION}

La financiación del volumen IX motivo de nuestro comentario, fue fruto de una labor que podríamos llamar titánica. Ya $€ n$ el informe presentado el año pasado señalábamos la muy difícil situación económica que estaba atravesando el órgano oficial de publicaciones de la Sociedad.

Como ustedes recordarán, en él señalábamos el esfuerzo tal 
vez infructuoso que la anterior dirección había llevado a cabo, para la publicación del tomo de las Memorias del II Congreso celebrado en Cali, y cómo después de dos años de su casi imposible realización, salió de manera algo tardía, perdiendo, sin duda, interés los temas presentados con tal motivo. De esta manera, sumando al aumento de costo de los números ordinarios curante los años 57-58, tuvimos que saldar la cuenta que nos gravó la publicación del libro y que a pesar de la propaganda hecha no alcanzó a amortizar ni la quinta parte de su valor. Es de anotar, que el volumen VIII tuvo un costo por edición de los 6 números, de $\$ 9.270,58$; en cambio el total de costo de publicación, comisiones, portes, etc., de este volumen, de acuerdo con el balance presentado a la directiva, ascendió a la suma de \$17.697,47 . Tal suma fue cubierta con el valor de propaganda en un $50 \%$; con el valor de antiguas cuotas cedidas por la sociedad a la Revista y catalogadas como de difícil cobro en un 20\%; y el resto, o sea el $30 \%$, por el valor de 180 suscripciones, venta de memorias, reimpresos, etc.

Este análisis económico escueto, da una idea de que, para no suspender la publicación o en mala hora llegar a desmejorarla, se tuvo que acudir a toda clase de recursos, entre los cuales cabe colocar en un primer lugar, la ayuda dada por la Sociedad al ceder su cartera atrasada hasta el 31 de diciembre de 1958; y algo más importante, a la realización de un proyecto largamente discutido en el Comité de Redacción, como fue el pago de suscripciones, y que en un futuro deberá normalmente acrecentar los fondos de la Revista y evitar que ésta se vea en el caso de desaparecer.

Para terminar, queremos hacer un llamamiento a todos los miembros de esta Sociedad y por su intermedio a todos los colecas vinculados al progreso de las ciencias médicas en el territorio nacional, para que se le preste toda la colaboración posible, científica, moral y económica a una realidad tangible, motivo de orgullo para todos nosotros, cual es la Revista Colombiana de Obstetricia y Ginecología, con diez años ininterrumpidos de labores, cuya dirección hoy entregaremos a la nueva Junta Directiva, con la seguridad de que sí se le apoya y se le estimula, no solo servirá de medio de unión científica y gremial entre todos los médicos que practicamos la especialidad, sino un motivo de justo orgullo en el mundo científico.

\section{Drs. Miguel A. Fernández-Bastidas y Guillermo López-Escobar Directores de la Revista Colombiana de Obstetricia y Ginecología.}

